\title{
CRM-BASED DYNAMIC DECISION-MAKING WITH HESITANT FUZZY INFORMATION FOR THE EVALUATION OF RANGELANDS
}

\author{
Xiaodi LIU ${ }^{1}$, Zengwen WANG ${ }^{\star}$, Shitao ZHANG ${ }^{1}$, Antoinette HETZLER ${ }^{3}$ \\ ${ }^{1}$ School of Mathematics and Physics, Anhui University of Technology, Ma'anshan, Anhui 243002, China \\ ${ }^{2}$ Researching Center of Social Security, Wuhan University, Wuhan, Hubei 430072, China \\ ${ }^{3}$ Department of Sociology, Lund University, Lund 22100, Sweden
}

Received 16 September 2017; accepted 10 June 2018

\begin{abstract}
As one of the important components of global land ecosystem, rangeland ecosystem has important value of ecosystem services. With the degeneration of rangeland in recent years, sustainability within rangeland ecosystem has become an increasingly important issue. The aim of this paper is to develop a novel dynamic decision-making approach based on hesitant fuzzy information to evaluate rangeland sustainability that considers ecological, social and economic aspects. Firstly, a modified satisfaction degree of alternative is presented, based on which a mathematical model for determining the stage weights is constructed. Secondly, the compromise ratio method (CRM), whose basic principle is that the optimal alternative should have the nearest distance from positive ideal solution and the longest distance from negative ideal solution simultaneously, is extended to accommodate hesitant fuzzy environment, and then adopted to tackle the dynamic decision-making with hesitant fuzzy information. Compared with the existing methods, the proposed method can eliminate the impact of attribute magnitude and dimension. Lastly, a numerical example on the evaluation of rangelands is provided to illustrate the practicality and superiority of the proposed method.
\end{abstract}

Keywords: hesitant fuzzy set, dynamic decision-making, compromise ratio method, satisfaction degree, rangeland sustainability evaluation.

JEL Classification: C44, C51, C61, C63, Q01.

\section{Introduction}

Rangeland, which is one of the most important ecological barriers, plays an important part in human existence and social development. Many semi-arid parts of the world, where precipitation is sufficient to support growth of forage but insufficient to regularly produce cultivated crops, are occupied by rangelands (Gross, Mcallister, Abel, Stafford Smith, \& Maru, 2006). As the basis of the socio-economic development, rangeland ecosystem, whose quality is interre-

${ }^{\star}$ Corresponding author. E-mail: wzwnjing@163.com

This is an Open Access article distributed under the terms of the Creative Commons Attribution License (http://creativecommons. org/licenses/by/4.0/), which permits unrestricted use, distribution, and reproduction in any medium, provided the original author and source are credited. 
lated with human residents' production and life, has caused wide public concern. As Pointed by Laflamme (2011), Natural environments around the world shape their human inhabitants, whose land management practices in turn shape their natural environments. Rangelands are regarded as having high conservation value and can provide a variety of ecosystem services in addition to social benefits (Farley, Walsh, \& Levine, 2017). As the most extensive kind of land cover, rangelands support tens of millions of people (Papanastasis, 2009). However, they are affected by many factors such as thin soils, aridity, low productivity per unit area and so on (Reeves \& Baggett, 2014). With the degradation of rangeland becoming an increasingly serious problem, people have paid attention to the sustainable development of rangelands (Campbell, Rodríguze, Ortiz, \& Gallegos, 2013; Abolhassani, Oesten, Rajmis, \& Azadi, 2013). Sustainability means that the needs of the present generation should be respected without impairing the future ones to meet current needs (Peano, Migliorini, \& Sottile, 2014; World Commission on Environment and Development, 1987). With the deepening research on the sustainable development of rangeland, the quantitative evaluation of rangelands has become a hotspot in the field of sustainable development research (Azadi, Shahvali, Berg, \& Faghih, 2007; Zendehedl, Rademaker, Baets, \& Huylenbroeck, 2010; Jakoby, Quaas, Müller, Baumgärtner, \& Frank, 2014). To support decisions on rangeland policy, the close links between economic, ecological and social processes must be addressed (Gross et al., 2006; Zendehedl, Rademaker, Baets, \& Huylenbroeck, 2009). Sustainability of rangeland ecosystem is influenced by comprehensive factors, such as global climate change, human production activities and the size of livestock (Campbell et al., 2013; Silva et al., 2017). Therefore, how to make effective evaluation for the rangelands seems to be an important and challenging task.

Usually, it is difficult to unify people's opinions when making evaluations. People often hesitate among several values to express their opinions and cannot reach an agreement. To tackle this situation, Torra (2010) proposed the concept of hesitant fuzzy set (HFS), which provides a new perspective for the study of decision theory (Rodríguez et al., 2016). As an extension of fuzzy set (Zadeh, 1965), HFS enables people to express their preference with several possible values between $[0,1]$. It is a flexible tool for decision-makers to express their hesitancy and has been applied to many areas since its appearance, such as decision making (Zhang, 2013; Alcantud, de Andrés Calle, \& Torrecillas, 2016; Wei, Alsaadi, Hayat, \& Alsaedi, 2016; Onar, Büyüközkan, Öztayşi, \& Kahraman, 2016), pattern recognition (Sun, Guan, Yi, \& Zhou, 2017), clustering analysis (Chen, Xu, \& Xia, 2013) and so on. Xia and Xu (2011) proposed the concept of hesitant fuzzy element (HFE), which is taken as the basic unit of HFS, and presented a series of aggregation operators, such as hesitant fuzzy weighting averaging (HFWA) operator, hesitant fuzzy weighted geometric (HFWG) operator, hesitant fuzzy hybrid averaging (HFHA) operator and so on. Wei (2012) proposed the hesitant fuzzy prioritized weighted aggregation operators and applied them to decision-making. Yu (2014) investigated the aggregation operators for multiplicative hesitant fuzzy information. Based on the traditional distance measures, such as Hamming distance, Euclidean distance and Hausdorff distance, a series of hesitant fuzzy distance measures were presented (Xu \& Xia, 2011). Farhadinia (2013) discussed the relationship between distance measure, similarity measure and entropy of HFSs. Novel information measures for hesitant fuzzy sets, such as distance measures (Hu, Zhang, Chen, \& Liu, 2016; Peng, Wang, \& Wu, 2016; Liu, Wang, \& 
Hetzler, 2017) and correlation coefficients (Meng \& Chen, 2015), have been proposed without adding any values into the shorter HFE. Zhu (2014) extended HFS to probability-hesitant fuzzy sets (P-HFSs). Furthermore, some traditional decision-making methods are extended to accommodate hesitant fuzzy environment (J. Q. Wang, D. D. Wang, Zhang, \& Chen, 2014; X. D. Liu, Zhu, Zhang, Hao, \& G. D. Liu, 2015). It is thus clear that HFS is an effective tool in aiding multiple attribute decision-making, the study of which is of great significance both in theory and application.

In fact, the current and past performance of alternatives needs to be taken into account in some complex decision-making problems. That is to say, the decision information is collected from different stages. We call such decision problem as dynamic decision-making or multiple stage decision-making. The dynamic decision-making is very common in everyday life, such as medical diagnosis, ecosystem efficiency dynamic evaluation, personnel dynamic examination and so on. However, among the studies above, the works related to dynamic decision-making with hesitant information are not as many as others. Only a few researchers have begun to explore this issue. Peng and Wang (2014) and Liao, Z. S. Xu and J. P. Xu (2014) proposed the dynamic hesitant fuzzy weighted averaging (DHFWA) operators to deal with the decision-making problem with hesitant fuzzy information. As we know, to determine the stage weights is the crux of the problem in dynamic decision-making. Peng and Wang (2014) adopted the linguistic quantifier to obtain the stage weights. However, this method neglects the observations at different stages or treats them as the same. Actually, as times goes by, the decision information will be updated and the fresh information is preferred. Hence, the latest data should be given more weight. Based on this principle and the average age of the data (Yager, 2008), Liao et al. (2014) presented a novel method to determine the stage weights. Compared with the existing methods (Nasibova \& Nasibov, 2010; Fullér \& Majlender, 2000; Filev \& Yager, 1995), Liao et al. (2014) have considered the variety of adjacent stages and thus more objective stage weights can be obtained. Through the analysis it can be found that problems existing in the dynamic decision-making with hesitant fuzzy information are in the following: (1) Although the variety of adjacent stages is taken into account, the technique for determining the stage weights requires strict hypothesis (Liao et al., 2014). (2) The HFWA and DHFWA operator are adopted to aggregate the attribute values (Peng \& Wang, 2014; Liao et al., 2014), and then the ranking of alternatives can be obtained. However, they ignore a fact that there is a difference between the cost and benefit attribute. Direct aggregation of the attribute values without considering the difference will lead to an unreasonable result. Moreover, the dimension of the obtained HFE will increase in the process of calculation, which may increase the calculation quantity in great range. In order to overcome the drawbacks mentioned above, a novel dynamic decision-making method with hesitant fuzzy information is presented and then applied to the evaluation of rangelands.

The remainder of this paper is organized as follows. Section 1 introduces some basic concepts related to HFSs. Section 2 puts forward a modified satisfaction degree of alternative, based on which a method for determining the stage weights is proposed, and then an approach to hesitant fuzzy dynamic decision-making based on CRM is presented. In Section 3, a numerical example on the evaluation of rangelands is provided to demonstrate the effectiveness and advantage of the proposed method. The last section ends the paper with some conclusions. 


\section{Preliminaries}

In this section, we review some basic concepts related to hesitant fuzzy set and the preliminaries used throughout the paper are introduced.

Definition 1 (Torra, 2010). Let $X$ be a reference set, a hesitant fuzzy set on $X$ is defined in terms of a function that when applied to $X$ returns a subset of $[0,1]$.

To be understood easily, the following mathematical symbol is adopted to express hesitant fuzzy set (Xia \& Xu, 2011):

$$
E=\left\{\left\langle x, h_{E}(x)\right\rangle \mid x \in X\right\},
$$

where $h_{E}(x)$ is a set of several values in [0,1], denoting the possible membership degrees of $x \in X$ to the set $E$. For convenience, Xia and Xu (2011) called $h=h_{E}(x)$ a hesitant fuzzy element (HFE).

Furthermore, some new operations of HFEs are defined as below (Xia \& Xu, 2011).

Definition 2. Let $h, h_{1}, h_{2}$ be three HFEs, then

(1) $h^{\lambda}=\bigcup_{\gamma \in h}\left\{\gamma^{\lambda}\right\}$

(2) $\lambda h=\bigcup_{\gamma \in h}\left\{1-(1-\gamma)^{\lambda}\right\}$;

(3) $h_{1} \oplus h_{2}=\bigcup_{\gamma_{1} \in h_{1}, \gamma_{2} \in h_{2}}\left\{\gamma_{1}+\gamma_{2}-\gamma_{1} \gamma_{2}\right\}$;

(4) $h_{1} \otimes h_{2}=\bigcup_{\gamma_{1} \in h_{1}, \gamma_{2} \in h_{2}}\left\{\gamma_{1} \gamma_{2}\right\}$.

In order to compare the HFEs, Xia and $\mathrm{Xu}$ (2011) gave the following comparison laws.

Definition 3. Let $h$ be a HFE. Then

$$
s(h)=\frac{1}{l} \sum_{\gamma \in h} \gamma
$$

is called the score function of $h$, where $l$ represents the number of the values in $h$. For any two HFEs $h_{1}$ and $h_{2}$, if $s\left(h_{1}\right)>s\left(h_{2}\right)$, then $h_{1}>h_{2}$; if $s\left(h_{1}\right)=s\left(h_{2}\right)$, then $h_{1}=h_{2}$.

Accordingly, the mean of HFS $E$ can be obtained.

Definition 4 (Liao, Xu, \& Zeng, 2015). Assume that $X$ is a reference set. Let $E=\left\{\left\langle x_{j}, h_{E}\left(x_{j}\right)\right\rangle \mid x_{j} \in X, j=1,2, \cdots, n\right\}$ be a HFS on $X$. The mean of HFS $E$ is defined as follows:

$$
s(E)=\frac{1}{n} \sum_{j=1}^{n} s\left(h_{E}\left(x_{j}\right)\right)=\frac{1}{n} \sum_{j=1}^{n}\left(\frac{1}{l_{j}} \sum_{\gamma_{j} \in h_{E}\left(x_{j}\right)} \gamma_{j}\right),
$$

where $l_{j}$ represents the number of the values in $h_{E}\left(x_{j}\right)$.

In order to aggregate hesitant fuzzy information, Torra and Narukawa (2009) put forward the aggregation principle of HFEs as follows.

Definition 5. Let $E=\left\{h_{i}, i=1,2, \cdots, n\right\}$ be a HFS with $n$ HFEs, $\Theta$ be a function on $E$, $\Theta:[0,1]^{N} \rightarrow[0,1]$, then

$$
\Theta_{E}=\bigcup_{\gamma \in\left\{h_{1} \times h_{2} \times \cdots \times h_{n}\right\}}\{\Theta(\gamma)\} .
$$

Based on the operations and aggregation principle of HFEs, Xia and Xu (2011) proposed the hesitant fuzzy weighting averaging (HFWA) operator for decision-making. 
Definition 6. Let $h_{j}(j=1,2, \cdots, n)$ be a collection of HFEs. A HFWA operator is a mapping $H^{n} \rightarrow H$ such that

$$
H F W A_{w}\left(h_{1}, h_{2}, \cdots, h_{n}\right)=\bigoplus_{j=1}^{n}\left(w_{j} h_{j}\right)=\bigcup_{\gamma_{1} \in h_{1}, \gamma_{2} \in h_{2}, \cdots \gamma_{n} \in h_{n}}\left\{1-\prod_{j=1}^{n}\left(1-\gamma_{j}\right)^{w_{j}}\right\},
$$

where $w=\left(w_{1}, w_{2}, \cdots, w_{n}\right)^{T}$ is the weighting vector of $h_{j}(j=1,2, \cdots, n)$ with $w_{j} \in[0,1]$ and $\sum_{j=1}^{n} w_{j}=1$.

In order to deal with time-based hesitant fuzzy arguments, Liao et al. (2014) and Peng and Wang (2014) proposed the dynamic aggregation operator for aggregating hesitant fuzzy information.

Definition 7. Let $t$ be the variable of time, then

$$
h(t)=\bigcup_{\gamma(t) \in h(t)}\{\gamma(t)\}
$$

is called a hesitant fuzzy variable, where $\gamma(t) \in[0,1]$.

Definition 8. Let $h\left(t_{k}\right)(k=1,2, \cdots, p)$ be a collection of hesitant fuzzy variables collected at $p$ different stages $t_{k}(k=1,2, \cdots, p)$. A dynamic hesitant fuzzy weighted averaging (DHFWA) operator is a mapping $H^{n} \rightarrow H$ such that

$\operatorname{DHFWA}_{\omega}\left(h\left(t_{1}\right), h\left(t_{2}\right), \cdots, h\left(t_{p}\right)\right)=\underset{k=1}{\oplus}\left(\omega\left(t_{k}\right) h\left(t_{k}\right)\right)=\bigcup_{\gamma\left(t_{k}\right) \in h\left(t_{k}\right), k=1,2, \cdots, p}\left\{1-\prod_{k=1}^{p}\left(1-\gamma\left(t_{k}\right)\right)^{\omega\left(t_{k}\right)}\right\}$,

where $\omega=\left(\omega\left(t_{1}\right), \omega\left(t_{2}\right), \cdots, \omega\left(t_{p}\right)\right)^{T}$ is the weighting vector of stages $t_{k}(k=1,2, \cdots, p)$ with $\omega\left(t_{k}\right) \in[0,1]$ and $\sum_{k=1}^{p} \omega\left(t_{k}\right)=1$.

In what follows, Yager (2008) introduced a new definition denoted by $\overline{A G E}$ to measure the average age of the data,

Definition 9. Let $t_{p}$ be the current time, then the age of the piece of data $x_{k}$ is $A G E\left(t_{k}\right)=p-k$. Thus, the average age of the data can be obtained as follows:

$$
\overline{A G E}=\frac{\sum_{k=1}^{p}\left(\omega\left(t_{k}\right) A G E(k)\right)}{\sum_{k=1}^{p} \omega\left(t_{k}\right)}=p-\sum_{k=1}^{p}\left(k \omega\left(t_{k}\right)\right) .
$$

Based on the well-known Hamming distance, Liu et al. (2017) proposed a novel hesitant fuzzy distance measure without adding any values into the shorter HFE.

Definition 10. Let $h_{1}$ and $h_{2}$ be two HFEs. Then a hesitant Hamming distance between two HFEs $h_{1}$ and $h_{2}$ can be defined as follows:

$$
d_{h h}\left(h_{1}, h_{2}\right)=\frac{1}{2}\left(\sqrt[l_{1}]{\prod_{\gamma_{1} \in h_{1}} \min _{\gamma_{2} \in h_{2}}\left|\gamma_{1}-\gamma_{2}\right|}+\sqrt[l_{2}]{\prod_{\gamma_{2} \in h_{2}} \min _{\gamma_{1} \in h_{1}}\left|\gamma_{2}-\gamma_{1}\right|}\right)
$$

According to Eq. (8), the distance between two HFEs can be calculated directly without arranging the values of all HFEs in increasing order and adding values into the shorter HFE. Therefore, it is more suitable to solve the hesitant fuzzy decision-making problem by using the distance measure above. 


\section{Dynamic decision-making under hesitant fuzzy environment}

In dynamic decision-making problem, it is sometimes not feasible to aggregate the attribute values directly in that there are different types of decision-making attributes. For instance, the benefit attribute and cost attribute, whose physical dimensions are different, cannot be aggregated directly. Hence, it is necessary to do the non-dimensional treatment of data for decision-making. To eliminate the impact of different measurements and physical dimensions on the decision results, a novel approach based on CRM and satisfaction degree of alternative is presented to tackle the hesitant fuzzy dynamic decision-making problem with stage weight information unknown.

\subsection{Problem description}

Dynamic multiple attribute decision-making (also called multi-stage multiple attribute decision-making) plays an important part in real-life situations, where the input arguments are collected at different stages. This paper focuses on a hesitant fuzzy dynamic multiple attribute decision-making problem with stage weights unknown.

For a dynamic decision-making problem with hesitant fuzzy information, let $\left\{Y_{1}, Y_{2}, \cdots, Y_{m}\right\}$ be the set of alternatives, $\left\{C_{1}, C_{2}, \cdots, C_{n}\right\}$ be the set of attributes, and $t_{k}(k=1,2, \cdots, p)$ be $p$ different stages, whose weighting vector is $\omega=\left(\omega\left(t_{1}\right), \omega\left(t_{2}\right), \cdots, \omega\left(t_{p}\right)\right)^{T}$, such that $\omega\left(t_{k}\right) \in[0,1]$ and $\sum_{k=1}^{p} \omega\left(t_{k}\right)=1$. Furthermore, assume that $w_{j}(j=1,2, \cdots, n)$ is the weight of the $j$ th attribute $C_{j}(j=1,2, \cdots, n)$, with $\sum_{j=1}^{n} w_{j}=1$ and $0 \leq w_{j} \leq 1(j=1,2, \cdots, n)$. Suppose that $D\left(t_{k}\right)=\left(h_{i j}\left(t_{k}\right)\right)_{m \times n}(i=1,2, \cdots, m ; j=1,2, \cdots, n ; k=1,2, \cdots, p)$ is the decision matrix with hesitant fuzzy information at the $k$ th stage, where $h_{i j}\left(t_{k}\right)$ denotes the HFE of the alternative $Y_{i}$ with respect to the attribute $C_{j}$ at the stage $t_{k}$.

Based on above all, the hesitant fuzzy dynamic decision-making problem can be expressed in dynamic decision-making matrices as below.

$$
D\left(t_{k}\right)=\left(h_{i j}\left(t_{k}\right)\right)_{m \times n}=Y_{1}\left(\begin{array}{cccc}
C_{1} & C_{2} & \cdots & C_{n} \\
h_{11}\left(t_{k}\right) & h_{12}\left(t_{k}\right) & \cdots & h_{1 n}\left(t_{k}\right) \\
h_{21}\left(t_{k}\right) & h_{22}\left(t_{k}\right) & \cdots & h_{2 n}\left(t_{k}\right) \\
\vdots & \vdots & \vdots & \vdots \\
h_{m 1}\left(t_{k}\right) & h_{m 2}\left(t_{k}\right) & \cdots & h_{m n}\left(t_{k}\right)
\end{array}\right), k=1,2, \cdots, p .
$$

\subsection{Method for determining the stage weighting vector}

\subsubsection{A novel satisfaction degree of alternative}

In most cases, the decision-makers with different professional backgrounds cannot reach a consensus of opinion. For example, opinions are divided when evaluating an alternative with respect to an attribute. Then the decision-makers' rating information can be expressed in the form of hesitant fuzzy set. Before presenting the main results, we first give the definition of satisfaction degree.

Definition 11 (Liao \& Xu, 2014). A satisfaction degree of the given alternative $Y_{i}$ over the attribute $C_{j}(j=1,2, \cdots, n)$ with the weight $w_{j}(j=1,2, \cdots, n)$ is defined as follows: 


$$
\Psi\left(Y_{i}\right)=\frac{(1-\theta) \sum_{j=1}^{n} w_{j} s\left(h_{i j}\right)}{\theta\left(1-\sum_{j=1}^{n} w_{j} s\left(h_{i j}\right)\right)+(1-\theta) \sum_{j=1}^{n} w_{j} s\left(h_{i j}\right)},
$$

where the parameter $\theta \in[0,1]$ is provided in advance by the decision-maker and $s\left(h_{i j}\right)$ denotes the score function of HFE $h_{i j}$.

However, when $\theta=1 / 2$, the satisfaction degree $\Psi\left(Y_{i}\right)$ is reduced to the weighted score function $\sum_{j=1}^{n} w_{j} s\left(h_{i j}\right)$, and much information will be lost. Moreover, the satisfaction degree $\Psi\left(Y_{i}\right)$, which is calculated based on the score function of HFE, cannot remove the impact of attribute magnitude and dimension. In multiple attribute decision making problem, there are different types of decision attributes, such as the benefit attribute and cost attribute. Since the physical dimensions or measurements of different quantitative attributes are different, direct calculation and comparison of decision data are not reasonable. In order to make the comprehensive evaluation value of each alternative comparable, the attribute values must be converted into a compatible scale. In view of these facts, we put forward a novel satisfaction degree for the given alternative $Y_{i}$ as below.

Definition 12. A novel satisfaction degree of the given alternative $Y_{i}$ over the attribute $C_{j}(j=1,2, \cdots, n)$ with the weight $w_{j}(j=1,2, \cdots, n)$ is defined as follows:

$$
\tilde{\Psi}\left(Y_{i}\right)=\frac{\sum_{j=1}^{n} w_{j} s\left(h_{i j}\right)}{\sum_{j=1}^{n} w_{j} v\left(h_{i j}\right)+\sum_{j=1}^{n} w_{j} s\left(h_{i j}\right)},
$$

where $s\left(h_{i j}\right)$ and $v\left(h_{i j}\right)$ denote the score function and variance function of HFE $h_{i j}$, respectively. The variance $v\left(h_{i j}\right)$ can be calculated according to the following formula:

$$
v\left(h_{i j}\right)=\sqrt{\frac{1}{l_{i j}} \sum_{\gamma \in h_{i j}}\left(\gamma-s\left(h_{i j}\right)\right)^{2}},
$$

where $l_{i j}$ denotes the number of values in $h_{i j}$. Especially, when $w_{j}=1 / n(j=1,2, \cdots, n), \tilde{\Psi}\left(Y_{i}\right)$ is reduced to the average satisfaction degree of alternative $Y_{i}$ as follows:

$$
\bar{\Psi}\left(Y_{i}\right)=\frac{\frac{1}{n} \sum_{j=1}^{n} s\left(h_{i j}\right)}{\frac{1}{n} \sum_{j=1}^{n} v\left(h_{i j}\right)+\frac{1}{n} \sum_{j=1}^{n} s\left(h_{i j}\right)} .
$$

The variance $v\left(h_{i j}\right)$ can reflect the level of disagreement among the decision-makers. Intuitively, the smaller the variance $v\left(h_{i j}\right)$ is, the higher the satisfaction degree is; while the larger the score $s\left(h_{i j}\right)$ is, the higher the satisfaction degree is. Furthermore,

$\tilde{\Psi}\left(Y_{i}\right)=\frac{\sum_{j=1}^{n} w_{j} s\left(h_{i j}\right)}{\sum_{j=1}^{n} w_{j} v\left(h_{i j}\right)+\sum_{j=1}^{n} w_{j} s\left(h_{i j}\right)}=\frac{1}{\sum_{j=1}^{n} w_{j} v\left(h_{i j}\right) / \sum_{j=1}^{n} w_{j} s\left(h_{i j}\right)+1}=\frac{1}{\phi_{w}\left(Y_{i}\right)+1}$, 
where $\phi_{w}\left(Y_{i}\right)$ denotes the coefficient of variation of alternative $Y_{i}$. Especially, when $n=1$, $\phi_{w}\left(Y_{i}\right)$ is reduced to the coefficient of variation of the HFE $h_{i j}$. That is to say,

$$
\phi_{w}\left(Y_{i}\right)=v\left(h_{i j}\right) / s\left(h_{i j}\right)=\sqrt{\frac{1}{l_{i j}} \sum_{\gamma \in h_{i j}}\left(\gamma-s\left(h_{i j}\right)\right)^{2}} / s\left(h_{i j}\right), n=1 .
$$

As a statistical measure, Coefficient of variation (CV) can be utilized to remove the impact of attribute magnitude and dimension (Li, Chen, \& Duan, 2010; Liu, 2016). As a dimensionless number, the $\mathrm{CV}$ can quantify the degree of variability relative to the mean and it is an effective tool when making comparisons between data sets with different units. Compared with the method (Liao \& Xu, 2014), the satisfaction degree proposed in this paper can be directly calculated without providing the numeric value of the parameter $\theta$ in advance, and what's more, it can eliminate the impact of different physical dimensions on the final decision.

\subsubsection{A novel method to determine the stage weights}

In the process of dynamic multiple attribute decision-making, the key issue is to determine the stage weighting vector (Liao et al., 2014). After the stage weights are obtained, we can easily aggregate the dynamic decision-making information and rank the alternatives. Undoubtedly, the observations in adjacent periods should not change significantly in the dynamic decision-making problem. On the other hand, more attention should be paid to the latest data samples. For these reasons, Liao et al. (2014) proposed a novel approach based on the average age of the data to determine the stage weighting vector, which is called the minimum average deviation (MAD) method.

$$
\left\{\begin{array}{l}
\min f(\omega)=\sum_{k=1}^{p}\left(\omega\left(t_{k}\right) s\left(\Delta h\left(t_{k}\right)\right)\right)^{2}+p-\sum_{k=1}^{p}\left(k \omega\left(t_{k}\right)\right), \\
\text { s.t. } \quad \sum_{k=1}^{p} \omega\left(t_{k}\right)=1, \omega\left(t_{k}\right) \geq 0, k=1,2, \cdots, p
\end{array}\right.
$$

where $s\left(\Delta h\left(t_{k}\right)\right)=s\left(h\left(t_{k}\right)\right)-s\left(h\left(t_{k-1}\right)\right)(k=2,3, \cdots, p)$, denoting the difference and deviation between adjacent stages, and $s\left(h\left(t_{k}\right)\right)$ is the score function of HFE $h\left(t_{k}\right)$, which is calculated by Eq. (2). For $k=1, s\left(\Delta h\left(t_{1}\right)\right)=s\left(\Delta h\left(t_{2}\right)\right)$. The theoretical base for Eq. (17) is to minimize the average deviation of the observations in adjacent stages and the average age of the data.

To solve the mathematical model above, a Lagrange function is constructed as follows:

$$
L(\omega(t), \lambda)=\sum_{k=1}^{p}\left(\omega\left(t_{k}\right) s\left(\Delta h\left(t_{k}\right)\right)\right)^{2}+p-\sum_{k=1}^{p}\left(k \omega\left(t_{k}\right)\right)+\lambda\left(\sum_{k=1}^{p} \omega\left(t_{k}\right)-1\right) .
$$

To obtain the stage weights $\omega\left(t_{k}\right)(k=1,2, \cdots, p)$ and $\lambda$, we differentiate Eq. (18) with respect to $\omega\left(t_{k}\right)(k=1,2, \cdots, p)$ and $\lambda$, and set the partial derivations equal to 0 .

$$
\left\{\begin{array}{l}
\frac{\partial L}{\partial \omega\left(t_{k}\right)}=2 s^{2}\left(\Delta h\left(t_{k}\right)\right) \omega\left(t_{k}\right)-k+\lambda=0, k=1,2, \cdots, p \\
\frac{\partial L}{\partial \lambda}=\sum_{k=1}^{p} \omega\left(t_{k}\right)-1=0
\end{array} .\right.
$$


Then the stage weights $\omega\left(t_{k}\right)(k=1,2, \cdots, p)$ and $\lambda$ can be derived by solving the following simultaneous equations:

$$
\left\{\begin{array}{l}
\omega\left(t_{k}\right)=\frac{k-\lambda}{2 s^{2}\left(\Delta h_{x}\left(t_{k}\right)\right)}, k=1,2, \cdots, p \\
\sum_{k=1}^{p} \frac{k-\lambda}{2 s^{2}\left(\Delta h_{x}\left(t_{k}\right)\right)}=1
\end{array} .\right.
$$

Obviously, the parameter $\lambda$ is shown in implicit function, which makes analytical solution of the stage weights $\omega\left(t_{k}\right)(k=1,2, \cdots, p)$ and $\lambda$ very hard. Furthermore, Eq. (17) is true under the condition that $s\left(\Delta h\left(t_{1}\right)\right)=s\left(\Delta h\left(t_{2}\right)\right)$, which is not in accordance with the fact. Finally, using the score function $s\left(\Delta h\left(t_{k}\right)\right)$ to measure the deviation between adjacent stages cannot eliminate the impact of attribute magnitude and dimension. In order to overcome these shortcomings, we propose an improved approach to determine the stage weights.

As the data is updated over time, new readings can be obtained continually in the dynamic decision-making problem. Therefore, the observations at different stages should not be treated as the same, and more weights should be assigned to the latest data (Liao et al., 2014), which indicates that we have a preference for the fresh data. Besides, the same alternatives at different stages are investigated, and thus there may exist autocorrelations between the observations at different stages. It is noted that the observations in adjacent periods should not change significantly. Then we take the minimum deviation of the observations at different stages and the $\overline{A G E}$ of the data as the objective function to construct a mathematical model. Based on the proposed satisfaction degree and the average age of the data (Yager, 2008), we present a novel approach to determine the stage weights as follows.

$$
\left\{\begin{array}{l}
\min \tilde{f}(\omega)=\sum_{k=1}^{p} \omega\left(t_{k}\right) \sum_{q=1, q \neq k}^{p}\left[\tilde{\Psi}\left(Y_{i}\left(t_{k}\right)\right)-\tilde{\Psi}\left(Y_{i}\left(t_{q}\right)\right)\right]^{2}+p-\sum_{k=1}^{p}\left(k \omega\left(t_{k}\right)\right), \\
\text { s.t. } \quad \sum_{k=1}^{p} \omega^{2}\left(t_{k}\right)=1, \omega\left(t_{k}\right) \geq 0, k=1,2, \cdots, p
\end{array}\right.
$$

where $\tilde{\Psi}\left(Y_{i}\left(t_{k}\right)\right)$ denotes the novel satisfaction degree of alternative $Y_{i}$ at the stage $t_{k}$.

To solve the mathematical model above, a Lagrange function is constructed as follows:

$$
\begin{aligned}
& L(\omega(t), \lambda)=\sum_{k=1}^{p} \omega\left(t_{k}\right) \sum_{q=1, q \neq k}^{p}\left[\tilde{\Psi}\left(Y_{i}\left(t_{k}\right)\right)-\tilde{\Psi}\left(Y_{i}\left(t_{q}\right)\right)\right]^{2}+p-\sum_{k=1}^{p}\left(k \omega\left(t_{k}\right)\right)+ \\
& \frac{\lambda}{2}\left(\sum_{k=1}^{p} \omega^{2}\left(t_{k}\right)-1\right) .
\end{aligned}
$$

To obtain the stage weights $\omega\left(t_{k}\right)(k=1,2, \cdots, p)$ and $\lambda$, we differentiate Eq. (22) with respect to $\omega\left(t_{k}\right)(k=1,2, \cdots, p)$ and $\lambda$, and set the partial derivations equal to 0 .

$$
\left\{\begin{array}{l}
\frac{\partial L}{\partial \omega\left(t_{k}\right)}=\sum_{q=1, q \neq k}^{p}\left[\tilde{\Psi}\left(Y_{i}\left(t_{k}\right)\right)-\tilde{\Psi}\left(Y_{i}\left(t_{q}\right)\right)\right]^{2}-k+\lambda \omega\left(t_{k}\right)=0, k=1,2, \cdots, p \\
\frac{\partial L}{\partial \lambda}=\sum_{k=1}^{p} \omega^{2}\left(t_{k}\right)-1=0
\end{array} .\right.
$$


Then the stage weights $\omega\left(t_{k}\right)(k=1,2, \cdots, p)$ can be derived:

$$
\omega\left(t_{k}\right)=\frac{k-\sum_{q=1, q \neq k}^{p}\left[\tilde{\Psi}\left(Y_{i}\left(t_{k}\right)\right)-\tilde{\Psi}\left(Y_{i}\left(t_{q}\right)\right)\right]^{2}}{\sqrt{\sum_{k=1}^{p}\left(k-\sum_{q=1, q \neq k}^{p}\left[\tilde{\Psi}\left(Y_{i}\left(t_{k}\right)\right)-\tilde{\Psi}\left(Y_{i}\left(t_{q}\right)\right)\right]^{2}\right)^{2}}}, k=1,2, \cdots, p .
$$

By normalizing the stage weights $\omega\left(t_{k}\right)(k=1,2, \cdots, p)$, we obtain

$$
\omega\left(t_{k}\right)=\frac{k-\sum_{q=1, q \neq k}^{p}\left[\tilde{\Psi}\left(Y_{i}\left(t_{k}\right)\right)-\tilde{\Psi}\left(Y_{i}\left(t_{q}\right)\right)\right]^{2}}{\sum_{k=1}^{p}\left(k-\sum_{q=1, q \neq k}^{p}\left[\tilde{\Psi}\left(Y_{i}\left(t_{k}\right)\right)-\tilde{\Psi}\left(Y_{i}\left(t_{q}\right)\right)\right]^{2}\right)^{2}}, k=1,2, \cdots, p .
$$

It is obvious that the theoretical base for Eq. (21) is basically the same as that for Eq. (17). However, the presented algorithm has three advantages over Liao et al's method: (1) Comparing Eq. (20) with (25), it can easily be seen that the stage weights can be directly calculated by solving Eq. (25), while solving Eq. (20) is more difficult. (2) The proposed approach, which is based on the novel satisfaction degree of alternative, can eliminate influence of dimension. In multiple attribute decision-making problems, direct aggregation of attribute values is sometimes impracticable in that there are different types of decision making attributes, such as the cost attribute and benefit attribute. The physical dimensions of different decision making attributes are different. Therefore, it is necessary to normalize the attribute values, the aim of which is to eliminate the influence of different physical dimensions on the final decision. This paper proposes a novel satisfaction degree of alternative based on coefficient of variation to determine the stage weights. Coefficient of variation, which is a statistical measure, can be utilized to remove the impact of different attribute dimensions and magnitude. (3) The method to determine the stage weights proposed by Liao et al. (2014) depends on the evaluation values at adjacent stages and $s\left(\Delta h\left(t_{1}\right)\right)=s\left(\Delta h\left(t_{2}\right)\right)$ is taken as a prerequisite for algorithm implementation. Moreover, the same alternatives at different stages are investigated, and thus there may exist autocorrelations between the observations at different stages. However, in Liao et al.s method, these autocorrelations are not seen between the observations at different stages, but only exist between the observations in adjacent stages, which results in that when using the model proposed by Liao et al. to determine the stage weights, $s\left(\Delta h\left(t_{1}\right)\right)=s\left(\Delta h\left(t_{2}\right)\right)$ is taken as premise of the model. In other words, the model will fail without the prerequisite. While in this paper, based on the evaluation values at different stages, the effectiveness of the proposed algorithm does not depend on the condition mentioned above and the autocorrelations between the observations at different stages can be reflected in the proposed method. 


\subsection{CRM under hesitant fuzzy environment}

CRM introduces a ranking index that can be used to reflect some balance between the shortest distance from the positive ideal solution and the longest distance from the negative ideal solution ( $\mathrm{Li}, 2007)$. It is a very useful tool for ranking alternatives and can overcome the defects caused by TOPSIS method. Moreover, the CRM considers the difference between the cost attribute and benefit attribute, and can remove influence of dimension. In this section, we extend the CRM to accommodate the hesitant fuzzy environment. The hesitant fuzzy CRM is then adopted to solve the dynamic decision-making problem.

Generally, attributes can be classified into two types, namely, the benefit attribute and cost attribute. That is to say, the set of attributes $C=\left\{C_{1}, C_{2}, \cdots, C_{n}\right\}$ can be partitioned into two disjoint subsets: $C^{1}$ and $C^{2}$, where $C^{1}$ denotes the subset of benefit attributes and $C^{2}$ denotes the subset of cost attributes. Moreover, $C=C^{1} \cup C^{2}$ and $C^{1} \cap C^{2}=\phi$, where $\phi$ is an empty set. The alternative $Y_{i}(i=1,2, \cdots, m)$ and attribute $C_{j}(j=1,2, \cdots, n)$ can be denoted by the vectors of HFS $Y_{i}=\left(h_{i 1}, h_{i 2}, \cdots, h_{i n}\right)$ and $C_{j}=\left(h_{1 j}, h_{2 j}, \cdots, h_{n j}\right)^{T}$ respectively, where $h_{i j}(i=1,2, \cdots, m, j=1,2, \cdots, n)$ represents the attribute value of the $i$ th alternative $Y_{i}$ under the $j$ th attribute. In the following, the hesitant fuzzy positive ideal solution and negative ideal solution are defined.

Definition 13. Let $Y_{i}=\left(h_{i 1}, h_{i 2}, \cdots, h_{i n}\right)(i=1,2, \cdots, m)$ be an alternative, where $h_{i j}$ denotes a HFE, then the vectors of hesitant fuzzy positive ideal solution $Y_{i}^{+}$and negative ideal solution $Y_{i}^{-}$can be defined as below, respectively:

and

$$
Y_{i}^{+}=\left(h_{1}^{+}, h_{2}^{+}, \cdots, h_{n}^{+}\right)
$$

$$
Y_{i}^{-}=\left(h_{1}^{-}, h_{2}^{-}, \cdots, h_{n}^{-}\right),
$$

where

and

$$
h_{j}^{+}= \begin{cases}\max _{1 \leq i \leq m}\left\{\gamma_{i j}, \gamma_{i j} \in h_{i j}\right\} & C_{j} \in C^{1} \\ \min _{1 \leq i \leq m}\left\{\gamma_{i j}, \gamma_{i j} \in h_{i j}\right\} & C_{j} \in C^{2}\end{cases}
$$

$$
h_{j}^{-}=\left\{\begin{array}{ll}
\min _{1 \leq i \leq m}\left\{\gamma_{i j}, \gamma_{i j} \in h_{i j}\right\} & C_{j} \in C^{1} \\
\max _{1 \leq i \leq m}\left\{\gamma_{i j}, \gamma_{i j} \in h_{i j}\right\} & C_{j} \in C^{2}
\end{array} .\right.
$$

Then, difference between each alternative $Y_{i}(i=1,2, \cdots, m)$ and the positive ideal solution $Y_{i}^{+}$can be calculated by using Eq. (9):

$$
d_{w}\left(Y_{i}, Y^{+}\right)=\sum_{j=1}^{n} \frac{1}{2}\left(\sqrt[l_{h_{i j}}]{\prod_{\gamma_{1} \in h_{i j}} \min _{2} \in h_{j}^{+}\left|\gamma_{1}-\gamma_{2}\right|}+\sqrt[l_{h_{j}^{+}}]{\prod_{\gamma_{2} \in h_{j}^{+}} \min _{1} \in h_{i j}\left|\gamma_{2}-\gamma_{1}\right|}\right) w_{j},
$$

where $l_{h_{i j}}$ and $l_{h_{j}^{+}}$denote the number of values in $h_{i j}$ and $h_{j}^{+}$, respectively. The smaller the distance $d_{w}\left(Y_{i}, Y^{+}\right)$is, the better the alternative $Y_{i}$ is. An alternative $Y_{i}^{*}$ satisfying

$$
d_{w}\left(Y_{i}^{*}, Y^{+}\right)=\min _{1 \leq i \leq m}\left\{d_{w}\left(Y_{i}, Y^{+}\right)\right\}
$$

is closest to the positive ideal solution. However, such an alternative may not guarantee to have the farthest distance from the negative ideal solution. 
Similarly, difference between each alternative $Y_{i}(i=1,2, \cdots, m)$ and the negative ideal solution $Y_{i}^{-}$can be calculated by using Eq. (9):

$$
d_{w}\left(Y_{i}, Y^{-}\right)=\sum_{j=1}^{n} \frac{1}{2}\left(\sqrt[l_{i j}]{\prod_{\gamma_{1} \in h_{i j}} \min _{\gamma_{2} \in h_{j}^{-}}\left|\gamma_{1}-\gamma_{2}\right|}+\sqrt[l_{h}^{-}]{\prod_{\gamma_{2} \in h_{j}^{-}} \min _{1} \in h_{i j}\left|\gamma_{2}-\gamma_{1}\right|}\right) w_{j},
$$

where $l_{h_{i j}}$ and $l_{h_{j}^{-}}$denote the number of values in $h_{i j}$ and $h_{j}^{-}$, respectively. The larger the distance $d_{w}\left(Y_{i}, Y^{-}\right)$is, the better the alternative $Y_{i}$ is. An alternative $Y_{i}^{\circ}$ satisfying

$$
d_{w}\left(Y_{i}^{\circ}, Y^{-}\right)=\max _{1 \leq i \leq m}\left\{d_{w}\left(Y_{i}, Y^{-}\right)\right\}
$$

is farthest from the negative ideal solution. However, such an alternative may not imply that it has the nearest distance from the positive ideal solution. We hope that $Y_{i}^{*}=Y_{i}^{\circ}$, but it may not occur.

Let

$$
\left\{\begin{array}{c}
d_{Y_{i}^{* *}}\left(Y^{+}\right)=\max _{1 \leq i \leq m}\left\{d_{w}\left(Y_{i}, Y^{+}\right)\right\} \\
d_{Y_{i}^{*}}\left(Y^{+}\right)=\min _{1 \leq i \leq m}\left\{d_{w}\left(Y_{i}, Y^{+}\right)\right\} \\
d_{Y_{i}^{\circ}}\left(Y^{-}\right)=\max _{1 \leq i \leq m}\left\{d_{w}\left(Y_{i}, Y^{-}\right)\right\} \\
d_{Y_{i}^{\circ \circ}}\left(Y^{-}\right)=\min _{1 \leq i \leq m}\left\{d_{w}\left(Y_{i}, Y^{-}\right)\right\}
\end{array} .\right.
$$

Then, a compromise ration for each alternative $Y_{i}(i=1,2, \cdots, m)$ is defined as below:

$$
\xi\left(Y_{i}\right)=x \frac{d_{Y_{i}^{* * *}}\left(Y^{+}\right)-d_{w}\left(Y_{i}, Y^{+}\right)}{d_{Y_{i}^{* *}}\left(Y^{+}\right)-d_{Y_{i}^{*}}\left(Y^{+}\right)}+(1-x) \frac{d_{w}\left(Y_{i}, Y^{-}\right)-d_{Y_{i}^{\circ \circ}}\left(Y^{-}\right)}{d_{Y_{i}^{\circ}}\left(Y^{-}\right)-d_{Y_{i}^{\circ \circ}}\left(Y^{-}\right)},
$$

where the parameter $x \in[0,1]$ represents the compromise coefficient. When $x=1$, the alternatives can be ranked by the distance $d_{w}\left(Y_{i}, Y^{+}\right)(i=1,2, \cdots, m)$. At this point, the distance between alternative and positive ideal solution is given more importance. When $x=0$, the alternatives can be ranked by the distance $d_{w}\left(Y_{i}, Y^{-}\right)(i=1,2, \cdots, m)$. Here, the distance between alternative and negative ideal solution is given more importance. The distances $d_{w}\left(Y_{i}, Y^{+}\right)$ and $d_{w}\left(Y_{i}, Y^{-}\right)$are given equal importance when $x=1 / 2$. Therefore, $x$ can be thought of as a compromise coefficient, and the index $\xi\left(Y_{i}\right)$ can be utilized as a yardstick to measure the extent of compromise that alternative $Y_{i}$ is proximate to the positive ideal solution $Y_{i}^{+}$and keeps away from the negative ideal solution $Y_{i}^{-}$. The larger the index $\xi\left(Y_{i}\right)$ is, the better the alternative $Y_{i}$ is.

Accordingly, the total compromise ration for each alternative $Y_{i}$ from $p$ different stages can be obtained as follows:

$$
E_{\omega}\left(Y_{i}\right)=\sum_{k=1}^{p} \omega_{k} \xi\left(Y_{i}\left(t_{k}\right)\right),
$$

where $\omega_{k}(k=1,2, \cdots, p)$ is the dynamic weight at the $k$ th stage and $\xi\left(Y_{i}\left(t_{k}\right)\right)$ denotes the compromise ration for alternative $Y_{i}$ at the $k$ th stage. Therefore, the greater the total compromise ration $E_{\omega}\left(Y_{i}\right)$ is, the better the comprehensive performance of the alternative $Y_{i}$ is. The optimal alternative can be selected according to the total compromise ration $E_{\omega}\left(Y_{i}\right)$. 


\subsection{An approach to dynamic decision-making with hesitant fuzzy information}

Based on the above analysis, a dynamic decision-making method with hesitant fuzzy information is summarized as below:

Step 1. In a dynamic decision-making problem with hesitant fuzzy information, the decisionmakers evaluate the alternatives $Y_{i}(i=1,2, \cdots, m)$ with respect to each attribute $C_{j}(j=1,2, \cdots, n)$ at the $k$ th stage, and the evaluation values are expressed in the form of HFEs. Thus, the hesitant fuzzy dynamic decision matrices $D\left(t_{k}\right)=\left(h_{i j}\left(t_{k}\right)\right)_{m \times n}$ at different stages, which are defined as shown in Eq. (10), can be constructed.

Step 2. Calculate the stage weights $\omega\left(t_{k}\right)(k=1,2, \cdots, p)$ according to Eq. (25).

Step 3. Identify the vectors of hesitant fuzzy positive ideal solution $Y_{i}^{+}$and negative ideal solution $Y_{i}^{-}$by Eq. (26) and (27), respectively, and calculate the compromise ration for each alternative $Y_{i}(i=1,2, \cdots, m)$ using Eq. (34).

Step 4. Calculate the total compromise ration for each alternative $Y_{i}$ at different stages by Eq. (35), and the alternatives can be ranked.

\section{Numerical example and comparative analysis}

Liao et al. (2014) presented a numerical example on the selection of suitable plan for rangeland area, which is adapted from Zendehedl et al. (2009). For the sake of comparison, the example in Liao et al.' study is adopted to demonstrate the effectiveness and superiority of the proposed method.

\subsection{An illustrative example}

As a complex ecosystem, the rangeland provides a lot of ecological economic and social services, including wildlife diversity, animal husbandry, recreational facilities, climate regulation, water supply, food, erosion control, ethical and social services and so on. Then, the rangeland has attracted a large amount of attention from social groups. The main social groups involved are as follows: citizens, environmental managers, ranchers, NGOs, range managers, watershed managers and nomad management departments (Zendehedl, Rademaker, Baets, \& Huylenbroeck, 2008). Different social groups show different concerns over the rangelands. For example, the rangers aim at increasing animal grazing rate to improve the profitability, while the environmental agencies and local citizens would like to minimize the activities of ranchers for maintaining biodiversity. To establish a policy for sustainable development, four plans have been instituted as follows:

$Y_{1}$ (Livestock control): Reduce the livestock by $40 \%$ in the area and introduce new legislation to facilitate grazing license transaction;

$Y_{2}$ (Rangeland rehabilitation): Introduce hand planting, seedling and a grazing system (no change in the number of animals);

$Y_{3}$ (Watershed management): Harvest water through contour furrow, gabion and biomechanical treatment, and reduce the livestock by $20 \%$ in the area;

$Y_{4}$ (Environmental preservation): Change the area into a National Park without any ranchers, and implement a number of plans for ecotourism and wildlife diversity. 
Suppose the social groups mentioned above have failed to reach agreement over the plans. To choose a suitable policy for ensuring that those services can be available for generations to come, the government resolved to test each plan for three years in four rangelands under the similar condition, and then select the optimal one to carry out in the near future. Every year, the four rangelands $Y_{i}(i=1,2,3,4)$ are evaluated with respect to three different attributes $C_{j}(j=1,2,3)$. A set of rules, which are shown in Table 1 , were used to help assess the four rangelands. $C_{3}$ is a cost attribute and the rest are benefit attributes. The weighting vector of the attributes is $w=(0.3,0.3,0.4)^{T}$.

Table 1. The rules of different attributes

\begin{tabular}{|l|l|l|l|}
\hline \multicolumn{1}{|c|}{ Atributes } & \multicolumn{3}{c|}{ Rules } \\
\hline Ecological attribute $C_{1}$ & Climate regulation & Soil conservation & Species diversity \\
\hline Social attribute $C_{2}$ & Cultural attributes & Social education & Recreation \\
\hline Economic attribute $C_{3}$ & Part-time job & Water supply & Cost of plan \\
\hline
\end{tabular}

Most of the rules are qualitative, and thus it is appropriate for the decision-makers to adopt fuzzy set to express their evaluation on alternatives. Nevertheless, more than one rule cannot be expressed simultaneously by the traditional fuzzy set. HFS is a useful tool that can be used to handle this situation. For example, there are three rules when measuring the ecological attribute. Hence, it is difficult to assess the alternative over the ecological attribute with the traditional fuzzy number, and HFS is well suited to express the evaluation value. That is to say, it is appropriate to take the attributes of the four plans as hesitant fuzzy variables. Once the evaluation values from different stages were determined, the dynamic decision-making matrices with hesitant fuzzy information were obtained, and thus it could be regarded as a hesitant fuzzy dynamic decision-making problem.

The proposed method is adopted to evaluate the four rangelands $Y_{i}(i=1,2,3,4)$ at three different stages, and the following steps are involved:

Step 1. Experts are invited to assess the four rangelands or plans $Y_{i}(i=1,2,3,4)$ with respect to three attributes $C_{j}(j=1,2,3)$, and the assessment values are collected from three years. The hesitant fuzzy decision matrices $D\left(t_{k}\right)=\left(h_{i j}\left(t_{k}\right)\right)_{4 \times 3}(k=1,2,3)$ at three different stages are constructed as shown in Tables $2-4$.

Table 2. Hesitant fuzzy decision matrix $D\left(t_{1}\right)$

\begin{tabular}{|c|c|c|c|}
\hline & $C_{1}$ & $C_{2}$ & $C_{3}$ \\
\hline$Y_{1}$ & $\{0.5,0.6\}$ & $\{0.4,0.6,1\}$ & $\{0.1,0.3,0.4\}$ \\
\hline$Y_{2}$ & $\{0,0.6,0.7\}$ & $\{0.1,0.3,0.5\}$ & $\{0.05,0.6\}$ \\
\hline$Y_{3}$ & $\{0,0.4,0.6\}$ & $\{0.1,0.3,0.5\}$ & $\{0.2,0.3,0.5\}$ \\
\hline$Y_{4}$ & $\{0.6\}$ & $\{0,0.7,0.8\}$ & $\{0.15,0.9,1\}$ \\
\hline
\end{tabular}


Table 3. Hesitant fuzzy decision matrix $D\left(t_{2}\right)$

\begin{tabular}{|c|c|c|c|}
\hline & $C_{1}$ & $C_{2}$ & $C_{3}$ \\
\hline$Y_{1}$ & $\{0.65,0.7\}$ & $\{0.4,0.7,1\}$ & $\{0.2,0.4,0.5\}$ \\
\hline$Y_{2}$ & $\{0,0.65,0.75\}$ & $\{0.15,0.4,0.6\}$ & $\{0.1,0.7\}$ \\
\hline$Y_{3}$ & $\{0,0.45,0.7\}$ & $\{0.15,0.4,0.6\}$ & $\{0.4,0.6\}$ \\
\hline$Y_{4}$ & $\{0.65,0.8\}$ & $\{0,0.8,0.9\}$ & $\{0.3,0.95,1\}$ \\
\hline
\end{tabular}

Table 4. Hesitant fuzzy decision matrix $D\left(t_{3}\right)$

\begin{tabular}{|c|c|c|c|}
\hline & $C_{1}$ & $C_{2}$ & $C_{3}$ \\
\hline$Y_{1}$ & $\{0.65,0.7,0.8\}$ & $\{0.6,0.8,1\}$ & $\{0.3,0.5,0.6\}$ \\
\hline$Y_{2}$ & $\{0,0.7,0.8\}$ & $\{0.2,0.5,0.7\}$ & $\{0.15,0.8\}$ \\
\hline$Y_{3}$ & $\{0,0.5,1\}$ & $\{0.2,0.5,0.7\}$ & $\{0.5,0.6,0.7\}$ \\
\hline$Y_{4}$ & $\{0.7,1\}$ & $\{0,0.9,1\}$ & $\{0.45,1\}$ \\
\hline
\end{tabular}

Step 2. We first calculate the satisfaction degree of each alternative $Y_{i}(i=1,2,3,4)$ for different stages using Eq. (12):

$$
\begin{aligned}
& \tilde{\Psi}\left(Y_{1}\left(t_{1}\right)\right)=0.7715, \tilde{\Psi}\left(Y_{2}\left(t_{1}\right)\right)=0.5817, \tilde{\Psi}\left(Y_{3}\left(t_{1}\right)\right)=0.6505, \tilde{\Psi}\left(Y_{4}\left(t_{1}\right)\right)=0.7001 ; \\
& \tilde{\Psi}\left(Y_{1}\left(t_{2}\right)\right)=0.8104, \tilde{\Psi}\left(Y_{2}\left(t_{2}\right)\right)=0.6014, \tilde{\Psi}\left(Y_{3}\left(t_{2}\right)\right)=0.7024, \tilde{\Psi}\left(Y_{4}\left(t_{2}\right)\right)=0.7173 ; \\
& \tilde{\Psi}\left(Y_{1}\left(t_{3}\right)\right)=0.8451, \tilde{\Psi}\left(Y_{2}\left(t_{3}\right)\right)=0.6166, \tilde{\Psi}\left(Y_{3}\left(t_{3}\right)\right)=0.7097, \tilde{\Psi}\left(Y_{4}\left(t_{3}\right)\right)=0.7171
\end{aligned}
$$

Then the stage weights $\omega\left(t_{k}\right)(k=1,2, \cdots, p)$ for different alternatives can be obtained by Eq. (25):

$$
\begin{aligned}
& \omega\left(Y_{1}\left(t_{1}\right)\right)=0.1660, \omega\left(Y_{1}\left(t_{2}\right)\right)=0.3338, \omega\left(Y_{1}\left(t_{3}\right)\right)=0.5002 \\
& \omega\left(Y_{2}\left(t_{1}\right)\right)=0.1665, \omega\left(Y_{2}\left(t_{2}\right)\right)=0.3334, \omega\left(Y_{2}\left(t_{3}\right)\right)=0.5001 \\
& \omega\left(Y_{3}\left(t_{1}\right)\right)=0.1660, \omega\left(Y_{3}\left(t_{2}\right)\right)=0.3336, \omega\left(Y_{3}\left(t_{3}\right)\right)=0.5004 \\
& \omega\left(Y_{4}\left(t_{1}\right)\right)=0.1666, \omega\left(Y_{4}\left(t_{2}\right)\right)=0.3333, \omega\left(Y_{4}\left(t_{3}\right)\right)=0.5001
\end{aligned}
$$

Step 3. According to Eq. (26) and (27), the hesitant fuzzy positive ideal solution $Y_{i}^{+}$and negative ideal solution $Y_{i}^{-}$at different stages can be determined:

$$
\begin{aligned}
& Y^{+}\left(t_{1}\right)=(\{0.7\},\{1\},\{0.05\}), Y^{-}\left(t_{1}\right)=(\{0\},\{0\},\{1\}) ; \\
& Y^{+}\left(t_{2}\right)=(\{0.8\},\{1\},\{0.1\}), Y^{-}\left(t_{2}\right)=(\{0\},\{0\},\{1\}) ; \\
& Y^{+}\left(t_{3}\right)=(\{1\},\{1\},\{0.15\}), Y^{-}\left(t_{3}\right)=(\{0\},\{0\},\{1\}) .
\end{aligned}
$$

The compromise ration for each alternative $Y_{i}(i=1,2, \cdots, m)$ at different stages can be calculated by Eq. (34):

$$
\begin{aligned}
& \xi\left(Y_{1}\left(t_{1}\right)\right)=1, \xi\left(Y_{2}\left(t_{1}\right)\right)=0.1906+0.3856 x, \xi\left(Y_{3}\left(t_{1}\right)\right)=(1-x) \cdot 0.2603, \xi\left(Y_{4}\left(t_{1}\right)\right)=0.8282 x ; \\
& \xi\left(Y_{1}\left(t_{2}\right)\right)=1, \xi\left(Y_{2}\left(t_{2}\right)\right)=0.0807+0.5481 x, \xi\left(Y_{3}\left(t_{2}\right)\right)=(1-x) \cdot 0.1180, \xi\left(Y_{4}\left(t_{2}\right)\right)=0.6362 x ; \\
& \xi\left(Y_{1}\left(t_{3}\right)\right)=1, \xi\left(Y_{2}\left(t_{3}\right)\right)=0.588 x, \xi\left(Y_{3}\left(t_{3}\right)\right)=(1-x) \cdot 0.0414, \xi\left(Y_{4}\left(t_{3}\right)\right)=0.0425+0.9390 x .
\end{aligned}
$$


Step 4. The total compromise ration for alternative $Y_{i}(i=1,2,3,4)$ can be obtained by Eq. (35):

$$
E_{\omega}\left(Y_{1}\right)=1, E_{\omega}\left(Y_{2}\right)=0.0586+0.541 x, E_{\omega}\left(Y_{3}\right)=(1-x) \cdot 0.1033, E_{\omega}\left(Y_{4}\right)=0.0213+0.8196 x .
$$

Therefore, the ranking of alternatives can be obtained as Figure 1:

(1) If $x \in[0,0.0694]$, then $Y_{1} \succ Y_{3} \succ Y_{2} \succ Y_{4}$;

(2) If $x \in(0.0694,0.0889]$, then $Y_{1} \succ Y_{2} \succ Y_{3} \succ Y_{4}$;

(3) If $x \in(0.0889,0.1339]$, then $Y_{1} \succ Y_{2} \succ Y_{4} \succ Y_{3}$;

(4) If $x \in(0.1339,1]$, then $Y_{1} \succ Y_{4} \succ Y_{2} \succ Y_{3}$,

where " $\succ$ " denotes "prior to". It implies that reducing the livestock by $40 \%$ in the area and introducing new legislation to facilitate grazing license transaction is the most suitable plan for the rangeland.

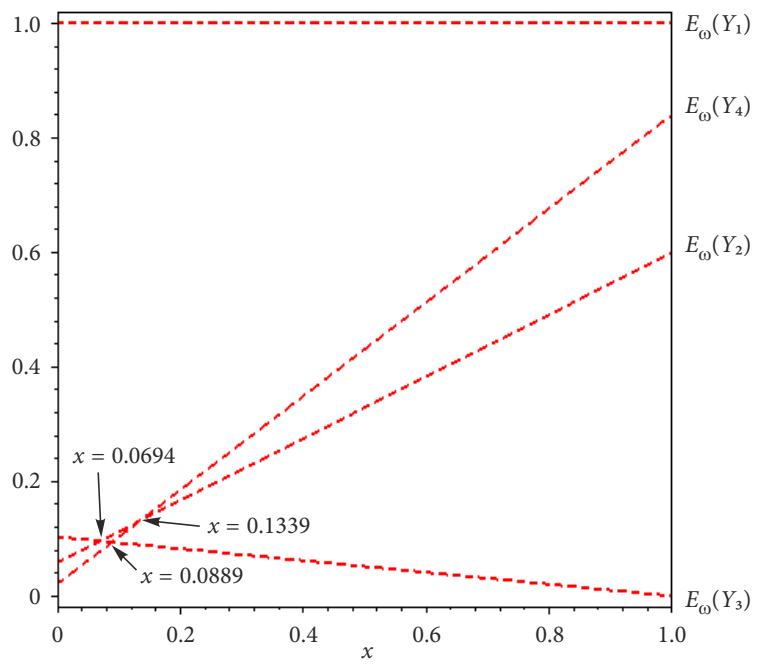

Figure 1. Decision results obtained by the CRM

\subsection{Comparative analysis}

\subsubsection{Comparison of the proposed method with the method based} on the MAD and dynamic hesitant fuzzy aggregation operators

Also, the problem above was studied by Liao et al. (2014). According to Eq. (5), they adopted the HFWA operator to aggregate the hesitant fuzzy variable at each stage. For example,

$h_{1}\left(t_{1}\right)=\{0.3319,0.3752,0.3958,0.4084,0.4319,0.4349,0.4467,0.4650,0.4687,0.4970,0.4996,0.5296,1\}$.

To save space, we will not list all the aggregated values. For details, see Liao et al. (2014).

To obtain the stage weights, they used Eq. (17) and assumed that $s\left(\Delta h\left(t_{1}\right)\right)=s\left(\Delta h\left(t_{2}\right)\right)$. For instance,

$$
\begin{aligned}
& s\left(\Delta h_{1}\left(t_{1}\right)\right)=s\left(\Delta h_{1}\left(t_{2}\right)\right)=0.0923, s\left(\Delta h_{1}\left(t_{3}\right)\right)=0.0810 \\
& s\left(\Delta h_{2}\left(t_{1}\right)\right)=s\left(\Delta h_{2}\left(t_{2}\right)\right)=0.0739, s\left(\Delta h_{2}\left(t_{3}\right)\right)=0.0784
\end{aligned}
$$




$$
\begin{aligned}
& s\left(\Delta h_{3}\left(t_{1}\right)\right)=s\left(\Delta h_{3}\left(t_{2}\right)\right)=0.1143, s\left(\Delta h_{3}\left(t_{3}\right)\right)=0.0631 \\
& s\left(\Delta h_{4}\left(t_{1}\right)\right)=s\left(\Delta h_{4}\left(t_{2}\right)\right)=0.0787, s\left(\Delta h_{4}\left(t_{3}\right)\right)=0.0180 .
\end{aligned}
$$

Then the stage weights can be obtained by Eq. (17) as follows:

$$
\begin{aligned}
& \omega\left(Y_{1}\left(t_{1}\right)\right)=0.0953, \omega\left(Y_{1}\left(t_{2}\right)\right)=0.2860, \omega\left(Y_{1}\left(t_{3}\right)\right)=0.6186 ; \\
& \omega\left(Y_{2}\left(t_{1}\right)\right)=0.1184, \omega\left(Y_{2}\left(t_{2}\right)\right)=0.3553, \omega\left(Y_{2}\left(t_{3}\right)\right)=0.5262 ; \\
& \omega\left(Y_{3}\left(t_{1}\right)\right)=0.0490, \omega\left(Y_{3}\left(t_{2}\right)\right)=0.1470, \omega\left(Y_{3}\left(t_{3}\right)\right)=0.8040 ; \\
& \omega\left(Y_{4}\left(t_{1}\right)\right)=0.0101, \omega\left(Y_{4}\left(t_{2}\right)\right)=0.0301, \omega\left(Y_{4}\left(t_{3}\right)\right)=0.9598 .
\end{aligned}
$$

By Eq. (7), the overall attribute values for each alternative $Y_{i}(i=1,2, \cdots, m)$ can be aggregated, and the ranking of alternatives can be obtained using Eq. (2):

$$
Y_{4} \succ Y_{1} \succ Y_{3} \succ Y_{2},
$$

where " $\succ$ " denotes "prior to". Thus, $Y_{4}$ is the optimal plan for the rangeland, which is different from that obtained by the proposed approach. The main cause of differences lies in the following.

Firstly, the methods for determining the stage weights are different. In Liao et al. (2014), the MAD method, i.e. Eq. (17), was utilized to determine the stage weights. Nevertheless, Eq. (17) is true under the condition that $s\left(\Delta h\left(t_{1}\right)\right)=s\left(\Delta h\left(t_{2}\right)\right)$, which does not accord with the fact. The model will fail without the prerequisite. Moreover, their method cannot eliminate the impact of attribute dimension and magnitude, which induces that the stage weights obtained change greatly (see Figure 2). $C_{3}$ is a cost attribute and the rest are benefit attributes. Since the physical dimensions of the decision making attributes are different, the attribute values cannot be aggregated directly and should be normalized. Otherwise, it will not get the reasonable results. In order to make the comprehensive evaluation value of each alternative comparable, the attribute values must be converted into a compatible scale. The novel satisfaction degree of alternative based on coefficient of variation is adopted to determine the stage weights. Coefficient of variation, which can quantify the degree of variability relative to the mean, is a dimensionless number and can eliminate the effect of different attribute dimensions ( $\mathrm{Li}$ et al., 2010). Therefore, small changes will happen in the stage weights obtained by the proposed method (see Figure 3 ).

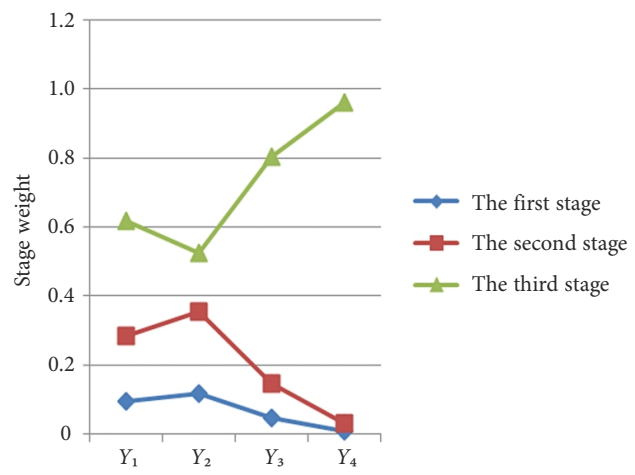

Figure 2. Stage weights obtained by the MAD method

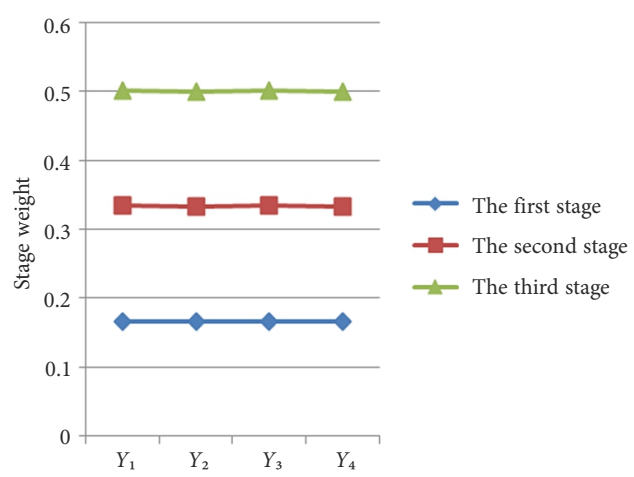

Figure 3. Stage weights obtained by the proposed method 
Secondly, Liao et al. (2014) adopted the HFWA operator and DHFWA operator to aggregate the attribute values, which call for much calculation effort. What's more, they did not differentiate between the cost attribute and benefit attribute, which will lead to completely different decision results. As we mentioned above, the cost attribute and benefit attribute cannot be aggregated directly in that their dimensions are different, and big errors may occur when aggregating directly. Thus, it is essential to conduct dimensionless processing for making the attribute values comparable. This paper presents a novel satisfaction degree of alternative based on coefficient of variation to determine the stage weights, and takes the CRM for data dimensionless. As a statistical measure, the coefficient of variation can be utilized to avoid the impact of attribute magnitude. In a word, this paper proposes a novel approach to dynamic decision-making with hesitant fuzzy information. No matter in the determination of the stage weights or in the aggregation of attribute values, the proposed method can well eliminate the impact of different physical dimensions, and thus a more objective and reasonable decision result can be obtained.

\subsubsection{Comparison of the proposed method with the method based} on linguistic quantifier and dynamic hesitant fuzzy aggregation operators

Peng and Wang (2014) also presented dynamic hesitant fuzzy aggregation operators to solve the multi-stage decision-making problems with hesitant fuzzy information. They adopted a linguistic quantifier-based method to determine the stage weights as follows:

$$
\omega\left(t_{k}\right)=(k / p)^{\alpha}-((k-1) / p)^{\alpha}, \alpha \geq 0, k=1,2, \cdots, p,
$$

where $\alpha$ indicates the decision strategies. It is found that different stages have been emphasized with the change of the parameter $\alpha$. According to Peng and Wang (2014), the stage weights are obtained as follows (Here, $\alpha=2$ ):

$$
\omega\left(t_{1}\right)=0.109, \omega\left(t_{2}\right)=0.340, \omega\left(t_{3}\right)=0.551 \text {. }
$$

By Eq. (7), all the hesitant fuzzy decision matrices $D\left(t_{k}\right)=\left(h_{i j}\left(t_{k}\right)\right)_{4 \times 3}(k=1,2,3)$ can be aggregated into a complex hesitant fuzzy decision matrix $\left(h_{i j}\right)_{4 \times 3}$. For example,

$$
\begin{aligned}
& h_{11}=\operatorname{DHFWA}_{\omega}\left(h_{11}\left(t_{1}\right), h_{11}\left(t_{2}\right), h_{11}\left(t_{3}\right)\right)=\bigcup_{\gamma\left(t_{k}\right) \in h\left(t_{k}\right), k=1,2,3}\left\{1-\prod_{k=1}^{3}\left(1-\gamma\left(t_{k}\right)\right)^{\omega\left(t_{k}\right)}\right\}= \\
& \{0.6361,0.6449,0.6547,0.6630,0.6658,0.6738,0.6828,0.6904,0.7327,0.7391,0.7463,0.7524\} \text {; } \\
& h_{12}=\{0.5201,0.6209,0.6373,0.6725,0.7412,0.7524,1\} \text {, }
\end{aligned}
$$

$h_{13}=\left\{\begin{array}{l}0.2471,0.2675,0.2797,0.3173,0.3357,0.3468,0.3583,0.3745,0.3757,0.3861,0.3914,0.4016,0.4328, \\ 0.4469,0.4482,0.4573,0.4619,0.4669,0.4708,0.4813,0.4900,0.4984,0.5120,0.5201,0.5286,0.5413,0.5490\end{array}\right\}$.

By Eq. (5), the overall attribute values for each alternative $Y_{i}(i=1,2, \cdots, m)$ can be aggregated, and the ranking of alternatives can be obtained using Eq. (2):

$$
Y_{4} \succ Y_{2} \succ Y_{1} \succ Y_{3} \text {, }
$$

Thus, $Y_{4}$ is the optimal plan for the rangeland, which is different from that obtained by the proposed approach. 
As the method proposed by Liao et al. (2014), Peng and Wang (2014) also utilized the hesitant fuzzy aggregation operators to deal with the dynamic decision-making problems with hesitant fuzzy information. Undoubtedly, it also increases the dimensions of the derived HFEs and calls for much calculation effort when adopting the hesitant fuzzy aggregation operators in the process of calculation. Moreover, in their method, they did not differentiate between the cost and benefit attributes, which could skew the final decision results. Last but not least, they proposed an approach based on linguistic quantifier to determine the stage weights, which neglect the autocorrelations between the observations at different stages. As mentioned above, the same alternatives at different stages are investigated. Therefore, there may exist autocorrelations between the observations at different stages. Although the method considers that more weights are assigned to the fresh data, it is not flexible enough to generate the stage weights for our dynamic decision-making problem. Compared with Peng and Wang's method (2014), the proposed method is computationally simple and fully considers the difference between the cost and benefit attributes and the autocorrelations between the observations at different stages.

\subsubsection{Comparison of the proposed method with hesitant fuzzy TOPSIS method}

$\mathrm{Xu}$ and Zhang (2013) proposed hesitant fuzzy TOPSIS method to deal with the hesitant fuzzy multiple attribute decision-making problems. For comparative purposes, we extend the hesitant fuzzy TOPSIS to accommodate dynamic environment. In their method, the shorter HFE is extended by adding the minimum value in it until the compared HFEs are of equal length. Then the hesitant fuzzy decision matrices $\tilde{D}\left(t_{k}\right)=\left(h_{i j}\left(t_{k}\right)\right)_{4 \times 3}(k=1,2,3)$ can be obtained as shown in Tables $5-7$.

Table 5. Hesitant fuzzy decision matrix $\tilde{D}\left(t_{1}\right)$

\begin{tabular}{|c|c|c|c|}
\hline & $C_{1}$ & $C_{2}$ & $C_{3}$ \\
\hline$Y_{1}$ & $\{0.5,0.5,0.6\}$ & $\{0.4,0.6,1\}$ & $\{0.1,0.3,0.4\}$ \\
\hline$Y_{2}$ & $\{0,0.6,0.7\}$ & $\{0.1,0.3,0.5\}$ & $\{0.05,0.05,0.6\}$ \\
\hline$Y_{3}$ & $\{0,0.4,0.6\}$ & $\{0.1,0.3,0.5\}$ & $\{0.2,0.3,0.5\}$ \\
\hline$Y_{4}$ & $\{0.6,0.6,0.6\}$ & $\{0,0.7,0.8\}$ & $\{0.15,0.9,1\}$ \\
\hline
\end{tabular}

Table 6. Hesitant fuzzy decision matrix $\tilde{D}\left(t_{2}\right)$

\begin{tabular}{|c|c|c|c|}
\hline & $C_{1}$ & $C_{2}$ & $C_{3}$ \\
\hline$Y_{1}$ & $\{0.65,0.65,0.7\}$ & $\{0.4,0.7,1\}$ & $\{0.2,0.4,0.5\}$ \\
\hline$Y_{2}$ & $\{0,0.65,0.75\}$ & $\{0.15,0.4,0.6\}$ & $\{0.1,0.1,0.7\}$ \\
\hline$Y_{3}$ & $\{0,0.45,0.7\}$ & $\{0.15,0.4,0.6\}$ & $\{0.4,0.4,0.6\}$ \\
\hline$Y_{4}$ & $\{0.65,0.65,0.8\}$ & $\{0,0.8,0.9\}$ & $\{0.3,0.95,1\}$ \\
\hline
\end{tabular}


Table 7. Hesitant fuzzy decision matrix $\tilde{D}\left(t_{3}\right)$

\begin{tabular}{|c|c|c|c|}
\hline & $C_{1}$ & $C_{2}$ & $C_{3}$ \\
\hline$Y_{1}$ & $\{0.65,0.7,0.8\}$ & $\{0.6,0.8,1\}$ & $\{0.3,0.5,0.6\}$ \\
\hline$Y_{2}$ & $\{0,0.7,0.8\}$ & $\{0.2,0.5,0.7\}$ & $\{0.15,0.15,0.8\}$ \\
\hline$Y_{3}$ & $\{0,0.5,1\}$ & $\{0.2,0.5,0.7\}$ & $\{0.5,0.6,0.7\}$ \\
\hline$Y_{4}$ & $\{0.7,0.7,1\}$ & $\{0,0.9,1\}$ & $\{0.45,0.45,1\}$ \\
\hline
\end{tabular}

According to $\mathrm{Xu}$ and Zhang (2013), the vectors of hesitant fuzzy positive ideal solution $Y^{+}\left(t_{k}\right)(k=1,2,3)$ and negative ideal solution $Y^{-}\left(t_{k}\right)(k=1,2,3)$ at different stages can be defined as below:

$$
\begin{aligned}
& Y^{+}\left(t_{1}\right)=(\{0.6,0.6,0.7\},\{0.4,0.7,1\},\{0.2,0.9,1\}) \\
& Y^{-}\left(t_{1}\right)=(\{0,0.4,0.6\},\{0,0.3,0.5\},\{0.05,0.05,0.4\}) \\
& Y^{+}\left(t_{2}\right)=(\{0.65,0.65,0.8\},\{0.4,0.8,1\},\{0.4,0.95,1\}) \\
& Y^{-}\left(t_{2}\right)=(\{0,0.45,0.7\},\{0,0.4,0.6\},\{0.1,0.1,0.5\}) \\
& Y^{+}\left(t_{3}\right)=(\{0.7,0.7,1\},\{0.6,0.9,1\},\{0.5,0.6,1\}) \\
& Y^{-}\left(t_{3}\right)=(\{0,0.5,0.8\},\{0,0.5,0.7\},\{0.15,0.15,0.6\}) .
\end{aligned}
$$

Then the relative closeness coefficient of alternative $Y_{i}\left(t_{k}\right)(i=1,2,3,4, k=1,2,3)$ with respect to $Y^{+}\left(t_{k}\right)(k=1,2,3)$ can be obtained as follows:

$$
\begin{aligned}
& R\left(Y_{1}\left(t_{1}\right)\right)=0.5244, R\left(Y_{2}\left(t_{1}\right)\right)=0.1864, R\left(Y_{3}\left(t_{1}\right)\right)=0.1762, R\left(Y_{4}\left(t_{1}\right)\right)=0.8045 \\
& R\left(Y_{1}\left(t_{2}\right)\right)=0.5869, R\left(Y_{2}\left(t_{2}\right)\right)=0.1971, R\left(Y_{3}\left(t_{2}\right)\right)=0.2483, R\left(Y_{4}\left(t_{2}\right)\right)=0.8225 \\
& R\left(Y_{1}\left(t_{3}\right)\right)=0.5855, R\left(Y_{2}\left(t_{3}\right)\right)=0.3404, R\left(Y_{3}\left(t_{3}\right)\right)=0.4892, R\left(Y_{4}\left(t_{3}\right)\right)=0.5719 .
\end{aligned}
$$

For the sake of comparison, we adopt the stage weights obtained by the proposed approach in Section 4.1. The total relative closeness coefficient of each alternative $Y_{i}(i=1,2,3,4)$ can be calculated using the following equation:

Therefore,

$$
R\left(Y_{i}\right)=\sum_{k=1}^{p} \omega_{k} \cdot R\left(Y_{i}\left(t_{k}\right)\right) .
$$

$$
R\left(Y_{1}\right)=0.5755, R\left(Y_{2}\right)=0.2670, R\left(Y_{3}\right)=0.3569, R\left(Y_{4}\right)=0.6942,
$$

which implies that $Y_{4} \succ Y_{1} \succ Y_{3} \succ Y_{2}$. Therefore, $Y_{4}$ is the optimal plan for the rangeland, which is different from that obtained by the proposed approach. Likewise, the hesitant fuzzy TOPSIS method proposed by Xu and Zhang (2013) did not differentiate between the cost and benefit attributes either. Moreover, the CRM introduces a ranking index that can be used to reflect some balance between the shortest distance from the positive ideal solution and the longest distance from the negative ideal solution, while the TOPSIS method is based on a function representing closeness to the positive ideal solution only ( $\mathrm{Li}, 2007)$. A detailed comparison of CRM and TOPSIS is presented in Li (2007). 
Through comparative analysis, we have found that the optimal plan obtained by the proposed method is $Y_{1}$, whereas the optimal plan obtained by the other two methods is $Y_{4}$. However, $C_{3}$ is a cost attribute and the rest are benefit attributes. Therefore, it is impracticable when directly aggregating the attribute values, and non-dimensional treatment for the attribute values should be produced. In this paper, a novel approach to dynamic decision-making with hesitant fuzzy information is presented, which can well avoid the impact of different attribute dimensions and magnitude. Compared with the existing methods, the proposed method, which is based on a novel satisfaction degree of alternative and the CRM, has the advantages as following.

1) In this paper, a novel satisfaction degree of alternative based on coefficient of variation is presented. It can reflect the level of disagreement among the decision-makers and remove the impact of different attribute dimensions and magnitude.

2) A novel method, which can reflect the autocorrelations between the observations at different stages and remove the impact of different attribute dimensions, is proposed to determine the stage weights. The proposed method fully considers the difference between the benefit and cost attributes, and can deal with the dynamic decision-making problems more effectively and reasonably.

3) The CRM, which is an effective tool to deal with decision-making problems, is extended to accommodate hesitant fuzzy environment. Compared with the method based on aggregation operators, the proposed method in this paper requires less calculation and is easy to handle. Besides, it can better evaluate the rangelands than the existing methods.

\section{Conclusions}

As an important branch of decision theory, dynamic decision-making problem has already aroused the attention from researchers. Due to its flexibility and convenience, HFS has been treated as a focus of recent academic attention. An intensive research on HFS has been conducted. Among these studies, only a few have focused on dynamic decision-making with hesitant fuzzy information. That is to say, the hesitant fuzzy decision-making problem with static information has already been investigated by many researchers. In order to enrich and perfect the theory of HFS, a novel approach is presented to deal with the hesitant fuzzy dynamic decision-making problem. Nondimensionalization processing will be carried in the decision-making process. As we know, the dynamic weighting vector is a key factor, which will influence the final decision results. In this paper, we have proposed a method based on a modified satisfaction degree of alternative to determine the stage weights. Besides, to eliminate the effect of different physical dimensions, we extend the CRM to accommodate hesitant fuzzy environment, and then aggregate the attribute values at different stages to rank the alternatives. Afterwards, a numerical example on the selection of an appropriate plan for the rangeland is given to illustrate the applicability of the proposed method, and the comparison of the results also shows the superiority of the dynamic decision-making method.

In future research, we will continue to focus on this topic, and pay attention to the dynamic risk decision-making problem with hesitant fuzzy information. 


\section{Acknowledgements}

The authors would like to thank the anonymous reviewers and the associate editor for their valuable comments and suggestions, which have helped us to improve the quality of this manuscript. This work was supported by the National Natural Science Foundation of China under Grant No. 71601002, 71673001 and 71704001; the Humanities and Social Sciences Foundation of Ministry of Education of China under Grant No. 16YJC630077; the Foundation for Young Talents in College of Anhui Province under Grant No. gxyqZD2018033; the major project of Humanities and Social Sciences of Ministry of Education of China under Grant No.16JJD840008 and Anhui Provincial Natural Science Foundation under Grant No. $1708085 \mathrm{MG} 168$ and 1808085QG224.

\section{References}

Abolhassani, L., Oesten, G., Rajmis, S., \& Azadi, H. (2013). Attitudes of rangeland holders towards sustainable range management in Iran: a case study of the Semnan rangelands. Rangeland Journal, 35(4), 435-443. https://doi.org/10.1071/RJ11079

Alcantud, J. C. R., de Andrés Calle, R., \& Torrecillas, M. J. M. (2016). Hesitant fuzzy worth: an innovative ranking methodology for hesitant fuzzy sets. Applied Soft Computing, 38: 232-243. https://doi.org/10.1016/j.asoc.2015.09.035

Azadi, H., Shahvali, M., Berg, J. V. D., \& Faghih, N. (2007). Sustainable rangeland management using a multi-fuzzy model: how to deal with heterogeneous experts' knowledge. Journal of Environmental Management, 83(2), 236-249. https://doi.org/10.1016/j.jenvman.2006.03.012

Campbell, W. B., Rodríguze, J. J., Ortiz, S. L., \& Gallegos, E. C. (2013). Does stocking rate manipulation promote pasture sustainability in the humid tropics? Rangeland Ecology \& Management, 66(3), 348-355. https://doi.org/10.2111/REM-D-11-00110.1

Chen, N., Xu, Z. S., \& Xia, M. M. (2013). Correlation coefficients of hesitant fuzzy sets and their applications to clustering analysis. Applied Mathematical Modelling, 37(4), 2197-2211. https://doi.org/10.1016/j.apm.2012.04.031

Farhadinia, B. (2013). Information measures for hesitant fuzzy sets and interval-valued hesitant fuzzy sets. Information Sciences, 240, 129-144. https://doi.org/10.1016/j.ins.2013.03.034

Farley, K. A., Walsh, K., \& Levine, A. S. (2017). Opportunities and obstacles for rangeland conservation in San Diego County, California, USA. Ecology and Society, 22(1), 38. https://doi.org/10.5751/ES-09077-220138

Filev, D., \& Yager, R. R. (1995). Analytic properties of maximum entropy OWA operators. Information Sciences, 85(1-3), 11-27. https://doi.org/10.1016/0020-0255(94)00109-O

Fullér, R., \& Majlender, P. (2000). An analytic approach for obtaining maximal entropy OWA operator weights. Fuzzy Sets and Systems, 124(1), 53-57. https://doi.org/10.1016/S0165-0114(01)00007-0

Gross, J. E., Mcallister, R. R. J, Abel, N., Stafford Smith, D. M., \& Maru, Y. (2006). Australian rangelands as complex adaptive systems: a conceptual model and preliminary results. Environmental Modelling \& Software, 21(9), 1264-1272.

https://doi.org/10.1016/j.envsoft.2005.04.024

Hu, J. H., Zhang, X. L., Chen, X. H., \& Liu, Y. M. (2016). Hesitant fuzzy information measures and their applications in multi-criteria decision making. International Journal of System Sciences, 47(1), 62-76. https://doi.org/10.1080/00207721.2015.1036476

Jakoby, O., Quaas, M. F., Müller, B., Baumgärtner, S., \& Frank, K. (2014). How do individual farmers' objectives influence the evaluation of rangeland management strategies under a variable climate? Journal of Applied Ecology, 51(2), 483-493. https://doi.org/10.1111/1365-2664.12216 
Laflamme, M. (2011). A framework for sustainable rangeland livelihoods. Rangeland Journal, 33(4), 339-351. https://doi.org/10.1071/RJ11023

Li, D. F. (2007). Compromise ratio method for fuzzy multi-attribute group decision making. Applied Soft Computing, 7, 807-817. https://doi.org/10.1016/j.asoc.2006.02.003

Li, W., Chen, G. F., \& Duan, C. (2010). Research and implementation of Index weight calculation model for power grid investment return. Lecture Notes in Computer Science, 6318, 44-52. https://doi.org/10.1007/978-3-642-16515-3_7

Liao, H. C., \& Xu, Z. S. (2014). Satisfaction degree based interactive decision making under hesitant fuzzy environment with incomplete weights. International Journal of Uncertainty, Fuzziness and Knowledge-Based Systems, 22(4): 553-572. https://doi.org/10.1142/S0218488514500275

Liao, H. C., Xu, Z. S., \& Xu, J. P. (2014). An approach to hesitant fuzzy multi-stage multi-criterion decision making. Kybernets, 43(9/10), 1447-1468. https://doi.org/10.1108/K-11-2013-0246

Liao, H. C., Xu, Z. S., \& Zeng, X. J. (2015). Novel correlation coefficients between hesitant fuzzy sets and their application in decision making. Knowledge-Based Systems, 82(C), 115-127. https://doi.org/10.1016/j.knosys.2015.02.020

Liu, S. T. (2016). A mathematical programming approach to sample coefficient of variation with interval-valued observations. TOP, 24, 1-18. https://doi.org/10.1007/s11750-015-0391-y

Liu, X. D., Wang, Z. W., \& Hetzler, A. (2017). HFMADM method based on nondimensionalization and its application in the evaluation of inclusive growth. Journal of Business Economics and Management, 18(4), 726-744. https://doi.org/10.3846/16111699.2017.1341848

Liu, X. D., Zhu, J. J., Zhang, S. T., Hao, J. J., \& Liu, G. D. (2015). Integrating LNMAP and TOPSIS methods for hesitant fuzzy multiple attribute decision making. Journal of Intelligent \& Fuzzy Systems, 28(1), 257-269.

Meng, F. Y., \& Chen X. H. (2015). Correlation coefficients of hesitant fuzzy sets and their application based on fuzzy measures. Cognitive Computation, 7(4), 445-463.

https://doi.org/10.1007/s12559-014-9313-9

Nasibova, R. A., \& Nasibov, E. N. (2010). Linear aggregation with weighted ranking. Automatic Control and Computer Sciences, 44(2), 96-102. https://doi.org/10.3103/S0146411610020057

Onar, S. Ç., Büyüközkan, G., Öztayşi, B., \& Kahraman, C. (2016). A new hesitant fuzzy QFD approach: an application to computer workstation selection. Applied Soft Computing, 46, 1-16. https://doi.org/10.1016/j.asoc.2016.04.023

Papanastasis, V. P. (2009). Restoration of degraded grazing lands through grazing management: can it work? Restoration Ecology, 17(4), 441-445. https://doi.org/10.1111/j.1526-100X.2009.00567.x

Peano, C., Migliorini, P., \& Sottile, F. (2014). A methodology for the sustainability assessments of agrifood systems: an application to the slow food president project. Ecology and Society, 19(4), 24. https://doi.org/10.5751/ES-06972-190424

Peng, D. H., \& Wang, H. (2014). Dynamic hesitant fuzzy aggregation operators in multi-period decision making. Kybernetes, 43(5), 715-736. https://doi.org/10.1108/K-11-2013-0236

Peng, J. J., Wang, J. Q., \& Wu, X. H. (2016). Novel multi-criteria decision-making approaches based on hesitant fuzzy sets and prospect theory. International Journal of Information Technology \& Decision Making, 15(3), 621-643. https://doi.org/10.1142/S0219622016500152

Reeves, M. C., \& Baggett, L. S. (2014). A remote sensing protocol for identifying rangelands with degraded productive capacity. Ecological Indicators, 43, 172-182.

https://doi.org/10.1016/j.ecolind.2014.02.009

Rodríguez, R. M., Bedregal, B., Bustincec, H., Dong, Y. C., Farhadinia, B., Kahramanf, C., Martínez, L., Torra, V., Xui, Y. J., Xud, Z. S., Herreraa, F. (2016). A position and perspective analysis of hesitant fuzzy sets on information fusion in decision making: towards high quality progress. Information Fusion, 29, 89-97. https://doi.org/10.1016/j.inffus.2015.11.004 
Silva, R. O., Barioni, L. G., Hall J. A. J., Carlos Moretti, A., Fonseca Veloso, R., Alexander, P., Crespolini, M., \& Moran, D. (2017). Sustainable intensification of Brazilian livestock production through optimized pasture restoration. Agricultural Systems, 153, 201-211.

https://doi.org/10.1016/j.agsy.2017.02.001

Sun, G. D., Guan, X., Yi, X., \& Zhou, Z. (2017). Grey relational analysis between hesitant fuzzy sets with applications to pattern recognition. Expert Systems with Applications, 92, 521-532. https://doi.org/10.1016/j.eswa.2017.09.048

Torra, V. (2010). Hesitant fuzzy sets. International Journal of Intelligent Systems, 25, 529-539. https://doi.org/10.1002/int.20418

Torra, V., \& Narukawa, Y. (2009). On hesitant fuzzy sets and decision. In The 18th IEEE International Conference on Fuzzy systems (pp. 1378-1382). Jeju Island, Korea.

Wang, J. Q., Wang, D. D., Zhang, H. Y., \& Chen, X. H. (2014). Multi-criteria outranking approach with hesitant fuzzy sets. OR Spectrum, 36(4), 1001-1019. https://doi.org/10.1007/s00291-013-0354-3

Wei, G. W. (2012). Hesitant fuzzy prioritized operators and their application to multiple attribute decision making. Knowledge-Based Systems, 31(7), 176-182. https://doi.org/10.1016/j.knosys.2012.03.011

Wei, G. W., Alsaadi, F. E., Hayat, T., \& Alsaedi, A. (2016). A linear assignment method for multiple criteria decision analysis with hesitant fuzzy sets based on fuzzy measure. International Journal of Fuzzy Systems, 19(3), 1-8. https://doi.org/10.1007/s40815-016-0177-x

World Commission on Environment and Development. (1987). Report of the world Commission on Environment and Development: our common future. Oxford: Oxford University Press.

Xia, M. M., \& Xu, Z. S. (2011). Hesitant fuzzy information aggregation in decision making. International Journal of Approximate Reasoning, 52(3), 395-407. https://doi.org/10.1016/j.ijar.2010.09.002

Xu, Z. S., \& Xia, M. M. (2011). Distance and similarity measures for hesitant fuzzy sets. Information Sciences, 181(11), 2128-2138. https://doi.org/10.1016/j.ins.2011.01.028

Xu, Z. S., \& Zhang, X. L. (2013). Hesitant fuzzy multi-attribute decision making based on TOPSIS with incomplete weight information. Knowledge-Based Systems, 52, 53-64. https://doi.org/10.1016/j.knosys.2013.05.011

Yager, R. R. (2008). Time series smoothing and OWA aggregation. IEEE Transactions on Fuzzy Systems, 16(4), 994-1007. https://doi.org/10.1109/TFUZZ.2008.917299

Yu, D. J. (2014). Group decision making under multiplicative hesitant fuzzy environment. International Journal of Fuzzy Systems, 16(2), 233-241.

Zadeh, L. A. (1965). Fuzzy sets. Information and Control, 8(3), 338-353. https://doi.org/10.1016/S0019-9958(65)90241-X

Zendehedl, K., Rademaker, M., Baets, B. D., \& Huylenbroeck, G. V. (2008). Qualitative valuation of environmental criteria through a group consensus based on stochastic dominance. Ecological Economics, 67(2), 253-264. https://doi.org/10.1016/j.ecolecon.2008.05.013

Zendehedl, K., Rademaker, M., Baets, B. D., \& Huylenbroeck, G. V. (2009). Improving tractability of group decision making on environmental problems through the use of social intensities of preferences. Environmental Modelling \& Software, 24(12), 1457-1466. https://doi.org/10.1016/j.envsoft.2009.05.017

Zendehdel, K., Rademaker, M., Baets, B. D., \& Huylenbroeck, G. V. (2010). Environmental decision making with conflicting social groups: a case study of the lar rangeland in Iran. Journal of Arid Environments, 74(3), 394-402. https://doi.org/10.1016/j.jaridenv.2009.09.011

Zhang, Z. M. (2013). Hesitant fuzzy power aggregation operators and their application to multiple attribute group decision making. Information Sciences, 234(10), 150-181.

https://doi.org/10.1016/j.ins.2013.01.002

Zhu, B. (2014). Decision method for research and application based on preference relation ( $\mathrm{PhD}$ thesis). Southeast University, Nanjing, China. 